\title{
LETRAMENTO E CONSTRUÇÃO DE IDENTIDADE NA TERCEIRA IDADE: UM ESTUDO DE CASO
}

\author{
Vidomar Silva Filho* \\ Rosângela Hammes Rodrigues
}

Resumo: Este artigo apresenta estudo de caso sobre o letramento, na esfera literária, de D., uma mulher idosa, com quatro anos de escolaridade formal. A partir da análise do bistórico de letramento de D., investiga-se a relação entre letramento e construção de identidade. Para fundamentar teoricamente o estudo, estabelecem-se distinções entre os modelos de letramento autônomo e ideológico. Apresentam-se os conceitos de prática, evento, agente e agência de letramento. Também se revisa o conceito de identidade. No estudo de caso, apresenta-se o histórico de letramento de D., buscando-se resgatar os usos da modalidade escrita por ela e sua família, desde a infância de D. até os dias atuais. Observa-se uma estreita relação entre o letramento de D. na esfera da literatura e a constituição paulatina de uma identidade de escritora, a qual the faculta expressar seu estar-no-mundo, recuperar e reconstruir suas memórias de infância e inserir-se em novos grupos sociais.

Palavras-chave: Letramento. Histórico de letramento. Agente de letramento. Agência de letramento. Construção de identidade.

Da minha vida fiz uma linda canção

Da minha história um poema

Da caneta a minha voz

Do papel o meu mensageiro

Que leva um pedido de paz para o mundo inteiro

(D., "Minha Vida", in Castelo de Pedras)

\section{INTRODUÇÃO}

Considerados os usos mais triviais da escrita e sua importância no desempenho das tarefas cotidianas, parece natural o direcionamento das atividades escolares de produção escrita para gêneros cuja ocorrência é mais frequente no cotidiano. É o que se vê, por exemplo, nos Parâmetros

\footnotetext{
* Doutorando do Programa de Pós-Graduação em Linguística da Universidade Federal de Santa Catarina. Email: vidomar1@gmail.com

** Professora do Programa de Pós-Graduação em Linguística da Universidade Federal de Santa Catarina.Email: hammes@cce.ufsc.br.
} 
Curriculares Nacionais (1 ${ }^{a}$ a $4^{a}$ série), que sugerem para o trabalho com escrita, gêneros do jornalismo (lide, notícia, anúncio classificado), da publicidade (anúncio, slogan, cartaz, folheto), do cotidiano (receita, instruções de uso, lista, rótulo, calendário, carta, bilhete, postal, cartão de aniversário, convite, diário pessoal) e didáticos (verbete de enciclopédia ou dicionário, textos expositivos), além de gêneros da esfera literária (conto, fábula, texto teatral, etc.) (BRASIL, 1997).

Essa preocupação com a exploração escolar de gêneros cuja ocorrência no universo social é mais provável também é externada em estudos que veem leitura e escrita na perspectiva do letramento ${ }^{1}$, como Soares (2009):

As pessoas se alfabetizam, aprendem a ler e a escrever, mas não necessariamente incorporam a prática da leitura e da escrita, não necessariamente adquirem competência para usar a leitura e a escrita, para envolver-se com práticas sociais de escrita: não lêem livros, jornais, revistas, não sabem redigir um ofício, um requerimento, uma declaração, não sabem preencher um formulário, sentem dificuldade para escrever um simples telegrama, uma carta, não conseguem encontrar informações num catálogo telefônico, num contrato de trabalho, numa conta de luz, numa bula de remédio... (SOARES, 2009, p. 45-46).

Entretanto privilegiar como critério para escolha dos gêneros a serem trabalhados em classe sua maior frequência leva a uma perspectiva essencialmente utilitarista, a qual, no seu extremo, pode propor que se excluam das atividades escolares de produção textual os gêneros da esfera da literatura, como se pode inferir em Kleiman (2007):

\footnotetext{
${ }^{1}$ Adotamos neste trabalho a abordagem ao letramento como fenômeno sócio-histórico, o qual se opõe à alfabetização, tomada como aprendizagem da leitura e escrita em uma perspectiva individual, como simples domínio do código escrito. Nossa perspectiva, portanto, é a mesma delineada por Tfouni (1995, p. 10): “O letramento [...] focaliza os aspectos sócio-históricos da aquisição da escrita. Entre outros casos, procura estudar e descrever o que ocorre nas sociedades quando adotam um sistema de escritura de maneira restrita ou generalizada; procura ainda saber quais práticas psicossociais substituem as práticas 'letradas' em sociedades ágrafas. Desse modo, o letramento tem por objetivo investigar não somente quem é alfabetizado, e, nesse sentido, desliga-se de verificar o individual e centraliza-se no social".
} 
A perspectiva [de letramento como prática social] não se exime de focalizar o impacto social da escrita, particularmente as mudanças e transformações sociais decorrentes das novas tecnologias e novos usos da escrita, com seus reflexos no homem. Esse foco necessariamente amplia a concepção do que venha a ser a escrita, antes reservada para os textos literários - de fato, os textos extraordinários que pouquissimos conseguem escrever passando a incluir os textos do cotidiano, os textos comuns do dia-a-dia, mesmo que sejam utilizados como recursos pedagógicos para construir a auto-segurança do aluno em relação à sua própria capacidade de ler e escrever (para que ele perceba que já domina muito dessa capacidade): listas, bilhetes, receitas, avisos, letreiros, "outdoors", placas de rua, crachás, camisetas e "buttons" de transeuntes, enfim, a escrita ambiental em sua enorme variedade passa a ser assim reconhecida e utilizada (KLEIMAN, 2007, p. 7, grifo nosso).

É inegável que o trabalho com a modalidade escrita na escola deva propiciar efetivo domínio dos usos sociais da escrita, mediante exploração de gêneros de maior frequência nas interações mediadas pela escrita, como os citados por Kleiman (2007) e por Soares (2009). Entretanto o texto literário não pode ser descartado como algo que "pouquíssimos conseguem escrever", nem como algo que prejudique a segurança dos alunos relativamente à própria capacidade de ler e escrever. Ao contrário, poderá auxiliar na construção de autoconfiança, além de levar seu autor a entender melhor a si próprio e ao seu entorno social e a expressar sua compreensão do mundo e da sua própria condição. Poderá também levar à participação em novas relações sociais e a redefinições na própria identidade.

O presente artigo, apesar de não trabalhar com uma situação de sala de aula, busca lançar luzes sobre a importância da produção do texto literário como uma possível forma de o indivíduo (re)elaborar visões a respeito do mundo e da própria existência e a desenvolver novas possibilidades de relação social, associadas a redefinições de identidade. Para isso, desenvolve-se estudo de caso em que se investiga a relação entre letramento na esfera literária e construção de identidade. Procurase mostrar como a produção do texto literário e a construção paulatina de uma identidade de escritora permitiram a D., uma mulher idosa, com 
apenas quatro anos de escolaridade formal, expressar seu estar-nomundo, recuperar e reconstruir suas memórias e inserir-se em novos grupos sociais.

A fim de assentar as bases teóricas deste trabalho, revisam-se estudos sobre o tema letramento. Estabelecem-se distinções entre os modelos de letramento autônomo e ideológico e apresentam-se os conceitos de prática, evento, agente e agência de letramento. Também se revisa o conceito de identidade.

No desenvolvimento do estudo de caso, buscam-se resgatar os usos da modalidade escrita por D. e por sua família, desde sua infância até os dias atuais. Analisa-se a forma como o letramento para os usos da escrita na esfera literária permitiu-lhe construir uma identidade de escritora. Também se avalia o papel de agências e agentes de letramento nesse processo.

\section{FUNDAMENTOS TEÓRICOS}

\subsection{Modelos autônomo e ideológico de letramento}

Os primeiros estudos sobre letramento/alfabetização, assim como muitos dos estudos atuais valorizam a escrita como um poderoso auxiliar do processo civilizatório. Segundo tal visão, a aquisição da escrita por uma dada comunidade, por si só, conduz a melhor organização social e, como consequência, a maior prosperidade. Isso pode ser visto neste trecho de Goody:

As potencialidades desse novo instrumento de comunicação [a escrita] podem afetar toda a gama das atividades humanas, políticas, econômicas, legais e religiosas. $\mathrm{Na}$ esfera administrativa, complexas organizações burocráticas dependem diretamente da escrita para organização de suas atividades, especialmente financeiras. Ela fornece um método confiável para a transmissão de informações entre o centro e a periferia e assim reduz as tendências à fissão que têm os grandes impérios. (GOODY, 1968, p. 1-2). 
Tal perspectiva do letramento funcionando, por si só, como elemento de progresso social e individual, é criticada por Street (1984), que a chama de modelo de letramento autônomo, uma vez que parte da premissa de que a escrita por si só, desvinculada de outros fatores sociais, tem efeitos sobre as práticas sociais e a cognição. Em trabalho posterior, Street assim se refere a esse modelo de letramento:

A perspectiva padrão em muitos campos, desde a escola até os programas de desenvolvimento, trabalha a partir do princípio de que o letramento em si - autonomamente - terá efeitos sobre outras práticas sociais e cognitivas. Apresentar o letramento a pessoas, vilas, jovens urbanos pobres, etc. 'iletrados' terá o efeito de aumentar suas habilidades cognitivas, melhorando suas perspectivas econômicas, fazendo-os cidadãos melhores, independentemente das condições sociais e econômicas que provocavam seu 'iletrismo' em primeiro lugar. Eu me refiro a isto como um modelo 'autônomo' de letramento. O modelo, eu proponho, disfarça os pressupostos ideológicos que o sustentam, de forma a que se apresente como neutro e universal e que o letramento como tal terá esses efeitos benignos. [...] A abordagem do letramento autônomo está simplesmente impondo as concepções de letramento ocidentais sobre outras culturas ou, dentro de um país, as concepções de uma classe ou grupo cultural sobre outros (STREET, 2003, p. 77).

Street (1984) também critica trabalhos de outros pesquisadores, que buscam demonstrar que pessoas de comunidades ágrafas ou iletradas têm capacidades cognitivas inferiores - por exemplo, menor habilidade de abstrair e de "pensar cientificamente" - aos membros de sociedades que utilizam a escrita nas interações cotidianas. $\mathrm{O}$ autor apresenta vários exemplos para ilustrar como membros de sociedades ditas primitivas podem engajar-se em práticas de natureza científica, como teste de hipóteses, e também para mostrar que muitos testes, pretensamente neutros, que revelariam diferenças nas formas de pensar, na verdade são culturalmente tendenciosos e revelam efeitos da escolarização: 
Por exemplo, quando Bernstein mostrou a crianças de classe baixa uma seqüência de figuras e lhes pediu que lhe contassem a história ali contida, elas começaram, por assim dizer, de dentro das fotos: 'ele atira a bola através da janela e a mulher os persegue', etc. [...]. As crianças de classe média, por outro lado, chamaram atenção explicitamente para as condições do teste: 'isso é uma figura; na figura aparece um menino chutando uma bola através de uma janela...' [...]. Para Bernstein, isso demonstra não simplesmente a convenção da expliciticidade que a criança de classe média aprendeu e reconheceu apropriada para este contexto [de testagem], mas o desenvolvimento de 'código elaborado', com todas as suas associações de abstração, lógica, etc. Poder-se-ia destacar que a criança de classe baixa considerou redundante referir-se constantemente à presença da figura, uma vez que sabia que o pesquisador estava presente e poderia vê-la por si próprio. Não havia necessidade de dizer 'uma' bola, 'uma' janela, porque o pesquisador estava olhando para elas também e então elas eram, em comum a ambos os observadores, 'a' bola, 'a' janela. [...] Aprender a enquadrar material escrito, particularmente em situações de teste, é uma convenção de nosso sistema educacional (STREET, 1984, p. 27-28).

Kleiman (1995) também tece severas críticas ao modelo autônomo de letramento e lista uma série de mitos relacionados ao letramento, "uma ideologia que vem se reproduzindo nos últimos trezentos anos e que confere ao letramento uma enorme gama de efeitos positivos, desejáveis, não só no âmbito da cognição [...] mas também no âmbito social" (KLEIMAN, 1995, p. 34). A autora arrola vários desses pretensos efeitos, exemplificando-os com trechos retirados de jornais. Segundo Kleiman, entre as consequências do letramento/alfabetização apontadas pelos jornais, incluem-se: manutenção das características da espécie contra uma possível degradação, integração à sociedade e à vida moderna, ascensão e mobilidade social, efeitos nos processos de desenvolvimento econômico, aumento na produtividade, emancipação feminina.

Ao modelo autônomo, Street (1984) contrapõe o modelo ideológico de letramento, o qual parte da premissa de que o letramento consiste em um conjunto de práticas sociais culturalmente específicas, com contornos bastante complexos: 
O modelo alternativo de letramento, ideológico, oferece uma visão culturalmente mais sensível das práticas de letramento à medida que elas variam de um contexto para outro. Esse modelo parte de premissas diferentes daquelas do modelo autônomo - ele propõe, ao contrário, que o letramento é uma prática social, não simplesmente uma habilidade técnica e neutra; que ele está sempre compreendido em princípios epistemológicos construídos socialmente. Diz respeito a conhecimento: as formas como as pessoas relacionam-se com a leitura e a escrita estão elas próprias enraizadas em concepções sobre conhecimento, identidade, ser. Também está compreendido em práticas sociais, tais como aquelas de um mercado de trabalho específico ou um de um contexto educacional específico, e os efeitos de aprender aquele letramento específico dependerão daqueles contextos específicos (STREET, 2003, p. 77-78).

A adoção do modelo ideológico de letramento implica que se levem em consideração as variáveis sociais ao se analisarem as causas e consequências dos usos da modalidade escrita por um indivíduo ou grupo de indivíduos. A variável domínio da escrita, tomada por si só, desvinculada de outras variáveis, mostra-se incapaz de dar conta, por exemplo, de sucesso ou insucesso profissional. A esse respeito, Street (1984) traz um exemplo bastante interessante e elucidativo, retirado de Graff: Dados demográficos do Canadá do século XIX sugerem que não é o domínio da escrita sozinho que decide quem fica com os melhores empregos, mas um conjunto de variáveis sociais, que incluem etnia e religião.

\subsection{Eventos e práticas de letramento}

Street (2003) cita trabalho anterior, de 1988, no qual estabelece a diferença entre eventos de letramento e práticas de letramento. A ideia de evento de letramento, segundo Street, está relacionada à noção sociolinguística de evento de fala. De acordo com Street (2003), a expressão foi usada inicialmente por Anderson, Teale e Estrada (1980), que definiram evento de letramento como uma ocasião na qual o indivíduo "tenta compreender sinais gráficos". Uma definição desse tipo ainda está fortemente presa ao paradigma cognitivista. Já em definição posterior de Heath, observa-se 
um deslocamento em direção ao paradigma sócio-histórico: “evento de letramento [é] qualquer ocasião em que uma porção de escrita seja parte integrante da natureza das interações dos participantes e dos seus processos interpretativos" (HEATH, 1982 apud STREET, 2003, p. 78). Kleiman (1995) cita como exemplo de evento de letramento a leitura de uma historinha para uma criança à hora de dormir. Fica evidente nesse exemplo que participar de um evento de letramento não implica necessariamente ser alfabetizado.

Já a expressão práticas de letramento, segundo Street (2003, p. 78), foi usada primeiramente em Street (1984) "como forma de enfocar as práticas e concepções sociais sobre leitura e escrita". Mais tarde, o autor usa o termo práticas de letramento para dar conta tanto do que Heath (1982) define como eventos de letramento quanto dos "modelos sociais de letramento que os participantes aplicam a esses eventos e que lhes dão sentido" (STREET, 2003, p. 78).

Deve ser observado que o mesmo evento de letramento pode configurar-se em práticas de letramento bastante diferentes. Heath (1982 apud STREET, 2003) traz, a esse respeito, exemplo bastante revelador. Comparando o evento leitura de historinhas para dormir em três comunidades diversas, Heath percebeu estratégias bastante diferenciadas. Numa das comunidades, a mais pobre e com menor escolarização, esse evento sequer ocorria. Nas outras duas comunidades, ambas de classe média, mas com níveis de escolarização diferentes, a leitura de histórias ocorria, porém com características bastante diversas, especialmente no papel esperado das crianças na interação.

\subsection{Agentes e agências de letramento}

Tomado o letramento, em uma perspectiva sócio-histórica, como resultado de um processo de apropriação da escrita em um contexto social determinado, é natural que se pense em mediadores para esse processo, em agentes humanos que medeiam semioticamente a aprendizagem sobre os usos da leitura e escrita. Esses seriam agentes de letramento. Para Bortoni-Ricardo, Machado e Castanheira (2010, p. 16), "todo professor é por definição um agente de letramento". Já a concepção de Kleiman (2006) para agente de letramento é bem mais restritiva. Para a autora, duas condições são necessárias aos agentes 
sociais: primeiro, constituir-se como articulador de uma ação coletiva, de acordo com os objetivos e interesses dos membros daquela coletividade; segundo, ser capaz de interagir com outros agentes sociais, buscando ação conjunta.

No presente trabalho, por conveniência de análise, optamos por uma definição mais aberta de agente de letramento, tomando como tal qualquer agente humano (indivíduo ou grupo) que medeie semioticamente a aprendizagem sobre algum uso social da modalidade escrita da língua, mesmo que essa ação mediadora não constitua prática consciente e sistemática visando produzir letramento.

O conceito de agência de letramento também varia entre os autores. Silva (2009) e Silva e Araújo (2010) tomam as agências de letramento como "áreas da vida dos sujeitos" ou "espaços sócio-discursivos":

Tal fato acontece porque algumas práticas letradas requeridas nos eventos que se configuram na agência digital são distintas das exigidas nos eventos presentes na agência acadêmica. [...]

Com isso, entendemos que a escola parece não ser mais a principal agência de letramento como defende Kleiman (1995), mas outras agências como a midiática [...], a religiosa e a familiar, por exemplo, vêm ganhando espaço socialmente e influenciando cada vez mais os sujeitos. [...]

[...] o contato que estabelecia com práticas letradas advindas de eventos de letramento oriundos da agência sindicalista da qual fez parte durante muito tempo, além das conversas com grandes intelectuais, como Antonio Candido, contribuíram, provavelmente, para que consolidasse as práticas requeridas pelos eventos característicos da agência política (comícios, negociações, pronunciamentos, etc.). (SILVA, 2009, p. 54-55, grifos nossos)

Defender que não há um Letramento com "L" maiúsculo e "o" no singular, porém múltiplos letramentos situados em contextos sociais e culturais nas sociedades em que surgem, significa atribuir-lhes o mesmo valor e, ao mesmo tempo, reconhecer a existência de letramentos associados com diferentes áreas da vida dos sujeitos - familiar, política, religiosa, educacional, profissional, entre outras. Tais áreas são denominadas de agência de letramento [...]. Desse modo, a noção de agência ultrapassa a concepção de 
lugar/ambiente físico, referindo-se a um espaço sócio-discursivo, no qual há eventos de letramento regidos por práticas letradas construídas socialmente pelos sujeitos participantes das agências (SILVA; ARAÚJO, 2010, p. 318, grifos nossos).

Para outros autores, as agências de letramento materializam-se como instituições ou grupos sociais. É o caso de Guimarães (2006, p. 61), que se refere à família como uma agência de letramento: "A família letrada, certamente, constitui a agência de letramento mais eficiente para garantir o sucesso escolar". Nessa concepção de agência de letramento, a instituição escola ocupa lugar de excelência, como se pode ver, por exemplo, em Jaeger (2003, p. 36-37): "No modelo autônomo, boa parte das vezes, letramento e escolarização ocorrem simultaneamente, pelo fato de a escola constituir, atualmente, em quase todas as sociedades, a principal agência de letramento". E também em Kleiman (2007) e em Pelandré e Aguiar (2009):

[...] e distinguir as múltiplas práticas de letramento da prática de alfabetização, tida como única e geral, mas apenas uma das práticas de letramento da nossa sociedade, embora possivelmente a mais importante, até mesmo pelo fato de ser realizada pela também mais importante agência de letramento, a instituição escolar. (KLEIMAN, 2007, p. 1-2, grifo nosso).

Para responder às novas necessidades sociais (que exigem um aprendizado de diferentes práticas de leitura e escrita muito além da decodificação do sistema de escrita alfabético) e compreender o motivo pelo qual a escola (principal agência de letramento) não consegue oportunizar ao sujeito o aprendizado das práticas culturais letradas de prestígio social, o conceito de letramento constitui auxílio para a compreensão dessas questões de ensinoaprendizagem da linguagem no meio escolar. (PELANDRÉ; AGUIAR, 2009, p. 56, grifo nosso).

Neste trabalho, tomar-se-ão como agências de letramento instituições ou grupos sociais em que se promovam eventos de letramento. Portanto, aqui, as agências de letramento materializam-se como loci, como ambientes no qual se dão letramentos, mediados pelos agentes de letramento, conforme definidos anteriormente. 


\subsection{Identidade}

A definição teórica do que seja identidade é uma questão complexa, dada a multiplicidade de conceitos de identidade, conforme o critério adotado para sua definição (filosófico, linguístico, psicológico, sociológico, etnológico, etc.). No caso específico da identidade social, que é o que nos interessa neste estudo, existem, segundo Penna (2001, p. 91), "inúmeras definições e empregos diferenciados da noção de identidade [...], sendo grande a diversidade (e mesmo ambiguidade) no emprego do termo". A autora argumenta que, dada essa indefinição, corre-se o risco de transpor para os estudos sociais a noção do senso comum, percebendo as diferenças entre pessoas como "parte da natureza das coisas, [...] como algo dado, inerente a um grupo ou indivíduo" (PENNA, 2001, p. 92). Contrapondo-se a essa noção simplista de identidade, Penna afirma:

[...] a identidade social é uma construção simbólica que envolve processos de caráter histórico e social, que se articulam (e atualizam) no ato de atribuição. Consideramos, assim, que a identidade social é uma representação, relativa à posição no mundo social, e portanto intimamente vinculada às questões de reconhecimento. Concebemos a possibilidade de múltiplas identidades, com base em referenciais distintos - como a origem territorial, a condição de gênero, a etnia, a atividade profissional etc. -, pois, enquanto uma construção simbólica, a identidade não é decorrência automática da materialidade. (PENNA, 2001, p. 9293).

Para Penna (2001, p. 108), a construção de identidade está intimamente associada às "condições de existência, [à] cultura e [às] relações sociais". Disso decorre que as possibilidades de construção identitária são mutáveis, conforme mudem as condições sociais. É isso que sugere Orlandi (2001, p. 204), ao afirmar que "a identidade é um movimento na história, [...] ela não é sempre igual a si mesma. Isto é, ela não é homogênea e ela se transforma. Não há identidades fixas e categóricas." Posição semelhante é expressada por Kleiman: 
Consideramos que a construção de identidades é constitutiva da realidade social das práticas discursivas, juntamente com outras construções, como a construção de relações sociais entre os falantes e a construção de sistemas de conhecimentos e crenças [...]. As identidades são (re)criadas na interação e por isso podemos dizer que a interação é também instrumento mediador dos processos de identificação dos sujeitos sociais envolvidos numa prática social. (KLEIMAN, 2001, p. 280-281).

Já Moita Lopes apresenta a construção de identidade como um processo permanente, associado à atividade discursiva:

Nesta visão do discurso como construção social através da qual os participantes constroem a realidade social e a si mesmos através do discurso [...], a construção da identidade social é vista como estando sempre em processo, pois é dependente da realização discursiva em circunstâncias particulares: os significados que os participantes dão a si mesmos e aos outros engajados no discurso. (MOITA LOPES, 2001, p. 307)

No presente trabalho, tomamos a identidade como uma construção simbólica constituída discursivamente, através de processos reconhecimento de pertinência do indivíduo em relação ao grupo. Como Penna, assumimos que o indivíduo representa-se e é representado em múltiplas identidades e, como Kleiman, Orlandi e Moita Lopes, consideramos a identidade uma construção mutável, dinâmica, em estreita ligação com as práticas sociais nas quais o indivíduo se engaja.

\section{ESTUDO DE CASO}

\subsection{Constituição do corpus}

Constituem os dados desta pesquisa uma pequena biografia e o histórico de letramento de D. R. S. S. Para construção desse corpus, inicialmente, foi realizada uma entrevista com D. em dezembro de 2010, na residência da entrevistada, no município de São José, SC. A seguir, 
uma vez que um dos autores deste artigo está na condição de insider, por ser filho de D., também se incorporaram aos dados certas informações que lhe eram acessíveis, concernentes a relações familiares, a alguns fatos e a características formais e temáticas dos textos produzidos por D., sem que fosse necessário perguntar sobre isso na entrevista. A versão final da biografia de D. e de seu histórico de letramento, sem a análise, foi lida para D., que não fez reparos, mas apenas acresceu algumas informações.

\subsection{Breve biografia de $\mathrm{D}$.}

Nascida em 1930, D. é a segunda mais nova de uma família com três filhos e cinco filhas, dos quais somente ela e uma irmã ainda vivem. Os pais eram analfabetos. Os irmãos estudaram somente até o segundo ano ou terceiro ano primário. D. não chegou a conhecer J., o irmão mais velho, que deixou a família aos 17 anos, no ano em que $\mathrm{D}$. nasceu.

D. começou a trabalhar ainda na infância, realizando pequenos serviços próprios das crianças de sua condição social nos anos 30. Por motivo de saúde e dificuldade de acesso, precisou abandonar a escola aos 12 anos, após concluir o antigo quarto ano primário.

Casou aos 23 anos e teve seis filhos. Seu marido, V., só cursara até o terceiro ano primário e trabalhava como pedreiro e, eventualmente, como músico. Mais tarde, tornou-se funcionário público. Algum tempo depois de casada, D. começou a costurar para ajudar no orçamento doméstico. Exerceu esse ofício de costureira durante 28 anos, até aposentar-se aos 55 anos.

Todos os filhos de D. frequentaram a escola. Dois não concluíram o ensino médio; um formou-se em Engenharia; outro (um dos autores deste artigo) graduou-se em Letras, concluiu mestrado e cursa atualmente doutorado; outro concluiu o ensino médio; outro formou-se em Direito. O genro é engenheiro civil, uma das noras é pedagoga. Exceto por um neto, todos os demais com idade suficiente concluíram ensino superior.

Aos 67 anos, D. ficou viúva. Há cerca de um ano, passou a morar junto à filha, mas em uma casa separada, onde leva vida bastante autônoma. Atualmente, aos 80 anos, D. goza de boa saúde física e mental. 


\subsection{Os letramentos de D.}

Nesta seção, alistam-se, em ordem temporal, os vários eventos e práticas de letramento nos quais D. se envolveu desde a infância até os dias atuais. Com isso, visa-se apresentar seu bistórico de letramento, o qual, segundo Silva e Araújo (2010, p. 316), diz respeito à "convivência [do sujeito] com práticas escolares e não escolares, advindas de diversas agências com as quais o sujeito mantém contato [e que] se influenciam mutuamente". Apõem-se ao histórico breves análises baseadas no referencial teórico aduzido.

\subsubsection{Da infância aos 65 anos}

Como já afirmado, os pais de D. eram analfabetos. Mas, segundo D., essa condição não parecia representar-lhes motivo de opróbrio ou impedimento de se engajarem em atividades de trabalho, comércio, religião, lazer.

No ambiente da casa paterna de D., o uso da escrita era raro. O irmão mais velho correspondia-se por cartas com a família. Estas, muito esparsas, eram lidas pelas irmãs de D., que também as respondiam. A família não recebia cartas de outras pessoas nem as mandava.

Inquirida sobre o uso de bilhetes na comunicação em casa, D. responde: "Ninguém usava bilhete. Ninguém escrevia." Também não se lia praticamente nada. D. diz que, durante a infância, só lia e escrevia na escola, que em casa só fazia as contas que trazia como deveres. A família não fazia contas em papel.

Segundo D., o dinheiro era pouco usado. Muito do que a família usava era obtido mediante escambo. A família comprava poucos produtos para consumo diário: fósforos, sal, querosene, sabão. Não havia pasta ou escova de dentes, nem sabonete. Inquirida sobre rótulos nos produtos, D. diz que alguns eram comprados a granel, como o sal. Ela não lembra com certeza, mas crê que havia rótulos nas caixas de fósforos e de sabão. A família não consumia medicamentos industrializados, mas apenas chás e outros remédios caseiros. 
No ambiente doméstico não havia nada escrito nas paredes, nem livros, ou qualquer outro tipo de material impresso, exceto pelos livros da escola:

D.: Não tinha nada na parede escrito, não tinha um pedaço de jornal, não tinha um pedaço de revista, [...] não tinha nada, nada, nada, nada pra ler. [...] Só o que eu lia era o livro da escola [...] e fazia os deveres.

A família frequentava regularmente a missa. Contudo, não lia nada na igreja e nem tinha bíblia em casa. D. diz que não lembra de alguma vez, durante a infância, de tomar um pedaço de papel para escrever ou de ler qualquer coisa que não fosse o livro da escola. Diz que aprendeu a ver as horas no relógio muito cedo. Mas só havia relógio na escola. Em casa, a família estimava as horas pela posição do sol e da lua.

Em criança, D. desejava ser professora, mas não brincava de escolinha. Nenhum dos brinquedos de que ela participava fazia uso da escrita. D. lembra que havia, na casa de sua avó, almanaques de farmácia, mas não tem certeza se os lia.

D. ingressou na escola com 8 anos e estudou até o quarto ano primário. As duas primeiras séries foram cursadas em uma escola multisseriada. Lembra de ter reprovado no primeiro ano, porque não havia quem a ensinasse em casa. $O$ terceiro e o quarto ano foram cursados num grupo escolar, em Palhoça, município vizinho a São José. D. tem impressão de que não chegou a concluir o último ano, mas cópia de seu histórico escolar (apresentada por D. durante a entrevista) mostra aprovação nos quatro anos. D. não era auxiliada pelos irmãos nas tarefas escolares.

$\mathrm{Na}$ escola multisseriada só se liam os textos dos livros didáticos, que eram fornecidos pelo Estado ${ }^{2}$. D. não soube responder se havia livros específicos para estudos sociais e matemática, mas lhe parece que não.

\footnotetext{
${ }^{2}$ Uma pesquisa na internet, com base em trechos de que D. lembra dos livros de leitura, revelou que os livros usados por D., um para cada ano escolar, eram os da Série Graduada de Leitura Fontes. Esta série, segundo Prochnow (2009), consistia de um livro de alfabetização e quatro de leitura e foi usada no antigo ensino primário de Santa Catarina desde os anos 20 até meados dos anos 50 do século XX.
}

SILVA FILHO; RODRIGUES - Letramento e construção de identidade... 
A escola multisseriada não tinha biblioteca. A leitura era em voz alta, tomada pela professora. Esta não pedia que os alunos escrevessem histórias. D. não lembra que a professora mandasse escrever outras coisas que não o alfabeto, palavras soltas, às vezes no quadro. D. diz que escreviam bastante nas folhas avulsas, mas não recorda exatamente o quê. Parece-lhe que seriam cópias do quadro, de pontos para serem decorados.

No grupo escolar, D. diz que escreviam mais e que havia mais matérias, entre as quais análise sintática. Havia provas ao final do ano. D. não lembra se havia outros livros nem se havia biblioteca no grupo escolar.

Apesar de D. haver frequentado a escola durante quatro anos, percebe-se que as práticas escolares de letramento não a levaram ao uso da modalidade escrita fora do ambiente escolar. Isso, muito provavelmente, se deve ao fato de que não havia práticas de letramento (STREET, 2003) no entorno social de D. Como já mencionado, a família de D. raramente fazia uso da escrita. O mesmo se pode dizer, a partir dos depoimentos de D., sobre a comunidade onde a família vivia. Uma das raras manifestações escritas era o pasquim, uma espécie de crônica social em forma de versos, de caráter satírico e malicioso. Era escrito anonimamente e afixado em local público, como a porta da venda. D. lembra de trechos desses textos, mas estes não eram lidos por ela e sim pelas irmãs, em voz alta.

Outra manifestação de escrita era o pão-por-deus, um tipo de cartão artesanal, recortado, desenhado e com uma quadrinha. D. relata que era muito comum a troca de pães-por-deus no fim do ano. Cita um pão-por-deus que fizeram as irmãs e que foi entregue, em nome de D., a um menino da vizinhança. Houve também troca de presentes entre D. e o menino.

Segundo D., as duas ou três casas comerciais da vizinhança não tinham letreiros. Mesmo uma mercearia de porte, que depois deu origem a uma grande rede de lojas, não ostentava nome na fachada. Era conhecida simplesmente como "a venda do Seu Raulino".

Essa ausência quase total da escrita na vida de D. avançou pela adolescência e idade adulta. D. relata que, enquanto namorou V., jamais trocaram cartas ou bilhetes. Mesmo quando, depois de casados, 
estiveram distantes durante alguns meses por razões profissionais, não usavam cartas, mas recados através de telefone.

Como costureira, D. começou a fazer uso mais frequente da escrita. Marcava em pedaços de papel os ajustes que precisavam ser feitos nas roupas dos clientes. Quando mandava algum dos filhos comprar aviamentos, também anotava em papel os itens a serem adquiridos, quantidades, cores.

Porém, exceto por esse uso profissional, D. continuava a valer-se da modalidade escrita apenas raramente. Ela e os filhos consumiam os chamados "remédios de farmácia", mas D. não lia as bulas. Nas farmácias, no fim do ano, distribuíam-se os almanaques, que eram lidos por ela, pelo marido e pelos filhos alfabetizados. Jornais e revistas dificilmente estavam disponíveis e D. não os lia. Apesar de D. e V. levarem os filhos a batizar na Igreja Católica, a família não frequentava a igreja. Também não tinham bíblia em casa. Nos anos 60 , D. adquiriu o livro As plantas curam, que lia esporadicamente, até emprestá-lo a alguém que não o devolveu.

D. não acompanhava os filhos nos deveres da escola. Quando a filha tornou-se adolescente, encarregava-se de matricular os irmãos e acompanhar os mais novos nas tarefas diárias. Com o ingresso dos filhos na escola, a família começou a adquirir livros didáticos. Comprou também um dicionário ilustrado e uma enciclopédia, mas D. não os lia, por falta de tempo.

A partir dos anos 70, livros, revistas e, eventualmente, jornais, tornaram-se comuns no ambiente doméstico. Mas quem os lia eram principalmente os filhos. Nas poucas vezes em que ia ao centro da cidade fazer compras, D. conhecia as lojas e não precisava ler os nomes das ruas para orientar-se. Após aposentar-se, por volta de 55 anos, D. passou a dedicar-se ao serviço da casa. Continuava lendo e escrevendo apenas eventualmente.

Pelo que se historicizou até aqui pode-se dizer que, durante boa parte da vida, D. foi alfabetizada mas envolveu-se muito pouco no que Street (2003) chama de práticas e eventos de letramento. Sua infância e adolescência transcorreram numa comunidade na qual o uso da escrita era extremamente restrito. A partir do retrato traçado por D., não é exagero afirmar que, na maioria das interações, a comunidade onde vivia 
dependia tão pouco da língua escrita, que se comportava quase como uma pequena sociedade ágrafa. Prova eloquente disso é o fato de que, apesar de D. ter-se alfabetizado e frequentado a escola durante quatro anos, não fazia uso da escrita em casa, nem nas brincadeiras infantis, nem no entorno social mais próximo (a igreja, os locais de trabalho e de comércio). Faltava também a D., nesse contexto, uma das condições que Soares (2009) considera necessárias ao letramento: a disponibilidade de material de leitura.

Essa situação de escassos usos da escrita nas interações cotidianas continuou pela adolescência e vida adulta de D. Mesmo suas atividades profissionais como costureira exigiam-lhe muito pouco uso da escrita, apesar de parte de sua clientela constituir-se de universitários. A entrada dos filhos na escola foi aos poucos modificando o entorno de D. no que diz respeito ao uso da modalidade escrita. Esse processo continuou ao longo dos anos, com vários dos familiares alcançando instrução superior. Assim, D. viu-se pouco a pouco inserida em um contexto letrado, bastante diferente daquele de sua infância. Mas isso ainda não foi suficiente para fazer com que ela se engajasse ativamente em interações mediadas pela escrita.

Percebe-se, então, que a aquisição escolar da escrita não teve grande impacto sobre a vida pessoal de D. desde a infância até os 65 anos. Portanto, no caso de D., não parece sustentar-se a tese proposta pelo modelo autônomo de letramento, a que se refere Street (1984), de que a mera aquisição da escrita provoque alterações substanciais nas condições de vida ou nas habilidades cognitivas. A partir do relato de D., fica evidente que as práticas sociais em que ela se envolveu em sua vida adulta prescindiram quase que completamente da modalidade escrita: casou-se, teve filhos, criou-os, trabalhou como costureira durante quase trinta anos, envolveu-se numa variedade de relações sociais com familiares, vizinhos, clientes, comerciantes, sem que fosse preciso ler e escrever praticamente nada. Ou seja, as múltiplas identidades criadas por D. (mãe, esposa, profissional) envolviam pouquíssimo letramento.

Isso começou a mudar quando D. tinha 65 ou 66 anos e, como forma de ocupar o tempo livre, passou a frequentar um curso sobre gerontologia promovido pela Universidade do Estado de Santa Catarina (UDESC). Nesse curso, forneciam-se muitos textos sobre cuidados com saúde, costumes de outros povos com relação aos idosos, entre outros 
tópicos. Segundo D., escrevia-se muito pouco, mas liam-se e comentavam-se os textos. Tem-se aqui, portanto, uma importante prática de letramento na vida de D., na qual o uso da modalidade escrita mediou aprendizagem de assuntos que, naquele momento, se mostravam relevantes para ela. Esta primeiro contato com a escrita em ambiente acadêmico, após tantos anos de pouquíssimo uso da escrita, pode ter auxiliado D. a tornar-se confiante para engajar-se em outras práticas letradas, como as que se descreverão a seguir.

\subsubsection{Aos 67 anos, a literatura}

Quando D. tinha 67 anos, seu marido faleceu repentinamente. Logo depois da morte do esposo, D. escreveu um poema em sua homenagem, "Sonho". A esse seguiu-se outro, "Sala perfumada", também falando sobre a ausência de V. Destaca-se que não parece ter havido intervenção aqui de qualquer agente de letramento. D. sequer convivia com alguém que usasse a escrita com fins estéticos.

Alguns meses depois da morte do esposo, D. começou a frequentar o NETI - Núcleo de Estudos da Terceira Idade da Universidade Federal de Santa Catarina (UFSC), onde participou, ao longo de oito anos, de vários cursos dirigidos a idosos. Segundo ela, não eram usados tantos textos impressos como no curso da UDESC. Mas escrevia-se mais, pois havia trabalhos escritos.

Mais tarde, houve, inclusive, quatro concursos de crônicas, dos quais D. participou, chegando a alcançar um segundo lugar. As crônicas versavam sobre o trabalho do NETI ou sobre a forma como os estudos ali desenvolvidos mudaram a vida de $\mathrm{D}$. Ela também participou de vários concursos literários nacionais promovidos por um banco, dirigidos especificamente a participantes da terceira idade.

Em 1998, D. soube de um concurso de poesia desenvolvido por uma padaria, em conjunto com o Grupo de Poetas Livres, e inscreveu um de seus poemas. Por conta disso, recebeu carta do GPL, convidando-a a participar do grupo. Incentivada por uma amiga, D. começou a frequentar as reuniões do grupo. Mas ia relutante, porque escrevera somente dois poemas e considerava que, com tão pouca instrução, teria dificuldade em integrar-se ao grupo. 
Contudo, apesar de a maioria dos membros do grupo ter maior tempo de escolaridade que D. (vários têm educação de nível superior), sua aceitação pelo grupo foi imediata e decisiva para seu processo de inserção num contexto de cultura letrada:

D.: Com o andamento da poesia das outras pessoas é que eu me entrosei no meio da poesia. Foi vendo os poetas. Foi vendo o trabalho das outras pessoas. [...] Aí eu comecei a prestar atenção como que as pessoas escreviam. Aí eu peguei e comecei a escrever. Eu comecei a escrever e a levar as poesias.

O reconhecimento pelo grupo é essencial à criação de identidade (PENNA, 2001). Assim, para que D. desenvolvesse uma identidade de escritora, foi decisivo ser reconhecida pelo GPL como tal desde o momento em que começou a frequentar as reuniões, mesmo sendo autora de apenas dois poemas até então. E a (auto)identificação de D. como escritora fez com que ela se envolvesse em outras práticas de letramento, as quais reforçaram essa identidade e lhe permitiram variadas formas de interação com o grupo, o que representa outra condição para criação de identidade (KLEIMAN, 2001). Eis algumas práticas mencionadas por D. na entrevista:

- No GPL, os membros leem escritos uns dos outros e também poemas de autores consagrados, como Drummond e Bandeira. Também leem e escrevem textos de outros gêneros, como conto e crônica.

- Os membros do grupo são frequentemente convidados para lançamentos de livros, exposições de arte, posses de academias de letras e eventos assemelhados.

- O GPL organiza antologias com textos de seus membros. O grupo também envia textos para publicações de outros grupos de escritores.

- O GPL publica a revista Ventos do Sul, de periodicidade irregular. 
- O grupo participa de um projeto, em conjunto com as empresas de ônibus de Florianópolis, intitulado "Viajando com poesia". Poemas são afixados nas janelas dos ônibus, para serem lidos pelos usuários.

- O GPL também desenvolve projeto em parceria com padarias, utilizando o saco de papel como suporte para poemas.

- O grupo se envolveu em projeto de urbanização da orla marítima do Continente, em parceria com a Prefeitura de Florianópolis. Bancos de uma praça foram ilustrados com trechos de poemas dos membros do grupo.

D. tem participado de todos esses projetos do GPL e tem-se valido deles para publicar dezenas de textos. Mas suas publicações mais importantes são dois livros, Casa de Barro (SILVA, 2005) e Castelo de Pedras (SILVA, 2008). O primeiro contém 80 poemas e seis textos em prosa. O segundo, 38 poemas e 13 textos em prosa. Um exame aos dois livros publicados por D. mostra que são temas frequentes em seus poemas: a vida na infância; a saudade; filosofia existencial simples; entes da natureza (vento, mar, árvore, garça, gaivota, lua, madrugada, pé de manacá, galo); a própria poesia; religiosidade; caos urbano; agressões à natureza; lendas; narrativas curtas com uma personagem solitária (poeta, velejador, pescador, andarilho, idosa). Os textos em prosa consistem principalmente em crônicas. O tema mais frequente são recordações de infância, mescladas a reflexões sobre a própria vida.

A forma preferida nos poemas são quadras, com versos heptassílabos, o que revela forte influência da poesia popular e da tradição oral. Mas também há muitos poemas em versos brancos e livres e dois poemas com versos decassílabos. Em Castelo de pedras, é comum o uso de rimas assonantes. $\mathrm{O}$ emprego desses recursos próprios de poesia mais culta fazem crer que a escrita de D. é efetivamente influenciada pelo contato com a escrita de outros poetas, nas práticas de letramento propiciadas pelo GPL.

Pelo que se apresentou até agora do bistórico de letramento de D., pode-se perceber que ela vai aos poucos estabelecendo uma nova relação 
com o mundo, que passa pelo uso da escrita no contexto da arte, da literatura. Assim, D. consegue resgatar sua própria história, expor suas ideias a respeito de si própria e do mundo, realizar um projeto de dizer que, possivelmente, se gestava havia anos. D. elabora, paulatinamente, para si uma identidade de escritora, à medida que se insere em novas relações sociais, mediadas pela escrita (nos cursos) ou construídas em torno dela (no GPL).

Para esse processo de construção de identidade por D., é decisiva a mediação de diversos agentes de letramento: os professores dos cursos que D. frequentou na UDESC e na UFSC, a professora do grupo de teatro, os colegas do Grupo de Poetas Livres, o filho e a nora que lhe revisam os textos, etc. Ainda que todos esses agentes tenham proporcionado que ela participasse em eventos de letramento, a principal agência de letramento em que ela se inseriu foi certamente o Grupo de Poetas Livres. Ali, pela mediação de colegas mais experientes, que se portam como agentes de letramento (mesmo sem noção clara disso), D. foi aos poucos ganhando conhecimento e segurança para escrever. Isso fica claro quando, inquirida sobre o fato de escrever tanto poemas em versos brancos e livres, como poesia rimada e com métrica, D. responde:

D.: Eu vejo os outros escrever. Eu digo: "Ah, se a pessoa escreve, eu também posso escrever".

A princípio, a transformação pela qual D. passou pareceu mais interna, mais pessoal. Mas, à medida que foi mostrando seus textos a outros, publicando-os onde podia, D. foi criando para si uma identidade de alguém que escreve poesia, a ser reconhecida como escritora incipiente, ainda que em um círculo restrito. Essa dupla orientação da identidade, subjetiva e social, é prevista por Kleiman (2001, p. 280), que entende a identidade "como um conjunto de elementos dinâmicos e múltiplos da realidade subjetiva e da realidade social, que são construídos na interação."

$\mathrm{Na}$ consolidação definitiva da identidade de D. como escritora, o lançamento dos dois livros ganha um sentido ritual. Em ambas as ocasiões, houve relativa pompa, com jantar ou coquetel, discursos, leitura de poemas, sessão de autógrafos e variadas homenagens de familiares e 
colegas. Esse rito do lançamento marca discursivamente a pertinência ao grupo dos escritores, o que é essencial à identidade (MOITA LOPES, 2001) e constitui ele próprio um importante evento de letramento (STREET, 2003), uma vez que se trata de uma interação constituída em torno da escrita.

No processo de construção de sua identidade de escritora, D. foi desenvolvendo novas formas de relação e novas formas de estar no mundo, mediadas pela escrita. Passou também a ser vista de outra forma e, por consequência, a provocar nos outros posturas diferentes com relação a sua pessoa. Esse efeito social do letramento (STREET, 2003) fica evidente no prefácio a Casa de Barro (SILVA, 2005, p. 2-3):

À medida que ela me mostrava mais e mais poemas, percebi que não se tratava de febre momentânea. Vi que se realizava, penosa e prazerosamente, uma vocação poética longamente adiada pela árdua luta para criar seus seis filhos. [...] Tive que me desvestir da fantasia de professor e entender que, ao tratá-la como aluna, estabelecia uma relação carinhosa, mas paternalista e desonesta. Tive que entender que a arte produzida por minha mãe tem um público específico, cujo gosto também deve ser respeitado.

[...] hoje, quando leio os textos de minha mãe, com seu linguajar simples, fortemente marcado pelo coloquial, com suas imagens concretas, apoiadas nas experiências de infância e na sua relação simples com o mundo, não a vejo mais como aluna. Longe disso. Reverencio-a como uma artista popular com a invejável capacidade de tocar o coração de um vasto público que, como ela, mantém uma relação direta e verdadeira com o mundo.

Apesar de ser a mais importante em termos de letramento, o GPL não é a única associação de que D. participa. Há cerca de dez anos, D. também faz parte da Academia Catarinense de Letras e Artes, da qual foi uma das fundadoras. Participa ainda de um grupo de teatro, sediado no teatro Adolpho Mello, em São José. Ali lê o roteiro das peças encenadas, para saber suas falas, e também já escreveu sua própria peça, que foi encenada pelo grupo várias vezes. 
Hoje D. costuma ler as antologias elaboradas pelo grupo, livros escritos por colegas e alguns livros esparsos. Lê também as peças que o grupo vem ensaiando. Escreve poemas (um ou dois por mês), preparando-se para publicar o terceiro livro. Também está trabalhando em um romance. E o contato com literatura permite a $\mathrm{D}$. constituir-se crítica do trabalho de colegas:

D.: Os poemas deles [alguns colegas] são poemas que a gente não sabe o que é que a pessoa tá dizendo. Como os do A. [um colega]... Os poemas do A. são muito bonito, mas são pras pessoas que têm estudo. [...] Agora os meus não [...]. É pro povão.

O fato de D. participar de várias práticas de letramento na esfera da literatura, ao ponto de elaborar críticas ao próprio trabalho e ao de outrem reforça a impressão de que ela efetivamente construiu para si uma nova identidade. E isso se deu a partir das práticas de letramento que a inserção em novas agências de letramento the proporcionou. Ao mesmo tempo, é a identidade de escritora que lhe faculta engajar-se em muitas dessas atividades de letramento. Portanto, no caso de D., parece que letramento e constituição de identidade estão intimamente entrelaçados.

Por fim, é interessante observar, no caso de D., a relativa independência entre alfabetização, compreendida como domínio do código escrito, e o letramento, tomado como "uma prática em que as pessoas usam os textos [escritos]" (DIONÍSIO, 2007, p. 210). Durante anos, D. foi alfabetizada porém sem quase utilizar a escrita. Já hoje, enquanto ela se engaja em práticas letradas, seus textos continuam sendo revisados pelo filho ou pela nora, para correção de ortografia e pontuação. Os muitos desvios em relação à norma escrita sugerem que D. não tem adquirido maior domínio sobre o código escrito, mas ela certamente aprendeu a usar a escrita para atender as suas necessidades estéticas e sociais. 


\section{CONSIDERAÇÕES FINAIS}

No estudo de caso aqui apresentado, observa-se que o letramento não é fator de inclusão social - pelo menos não no sentido de ascensão a uma classe social economicamente mais afluente. Também não tem propriamente caráter instrumental, não representa forma de potencializar a realização de tarefas cotidianas, como as citadas por Soares (2009), ou a participação na vida política.

No caso de D., o letramento tem efeito sobre a construção de identidade e lhe faculta a realização de um projeto de dizer. Permite que D. reconstrua a própria história e mostre a seus leitores sua versão pessoal de um mundo que já não existe: a comunidade rural onde viveu sua infância. Permite-lhe ainda expressar a maneira como vê o mundo de hoje e também posicionar-se a respeito de vários temas, entre os quais a literatura. Assim, D. pode hoje ocupar uma posição discursiva à qual não tinha acesso, o que lhe confere novas possibilidades de dizer. Por sua vez, a nova identidade também possibilita a D. o engajamento em novas práticas de letramento.

Finalmente, retomando a questão das práticas escolares com que iniciamos o artigo, esperamos ter ilustrado o fato de que a escritura de poemas ou contos não significa necessariamente um entrave ao desenvolvimento da autoconfiança ao escrever. Ao contrário, se a produção de escrita for socialmente situada, se ocorrer num contexto de letramento escolar organizado de forma a que o aluno sinta que seu dizer tem sentido (para si e os outros) e é valorizado, os textos da esfera da literatura oferecem-se como excelente escolha, com a vantagem adicional de que o aluno tem possibilidade de exercitar a sensibilidade e o pensar a própria existência.

\section{REFERÊNCIAS}

ANDERSON, A. B.; TEALE, W. H.; ESTRADA, E.. Low-income children's preschool literacy experiences: some naturalistic observations. The Quarterly Newsletter of the Laboratory of Comparative Human Cognition, San Diego, UCSD, v. 2, n. 3, p. 59-65, Jul. 1980. Disponível em:

<http://lchc.ucsd.edu/Histarch/j180v2n3.PDF>. Acesso em: 15 ago. 2012. 
BORTONI-RICARDO, S. M.; MACHADO, V. R.; CASTANHEIRA, S. F. Formação do professor como agente letrador. São Paulo:Contexto, 2010.

BRASIL. Secretaria de Educação Fundamental. Parâmetros Curriculares Nacionais $\left(1^{a}\right.$ a $4^{a}$ séries $)$. Volume 2. Língua Portuguesa. Brasília: Secretaria de Educação Fundamental, 1997. Disponível em:

http://portal.mec.gov.br/seb/arquivos/pdf/livro02.pdf. Acesso em 22/1/2011.

DIONÍSIO, M. de L. Educação e os estudos atuais sobre letramento. Entrevista concedida por Maria de Lourdes Dionísio, da Universidade do Minho, a Nilcéia Lemos Pelandré e Adriana Fischer. Perspectiva, Florianópolis, v. 25, n. 1, p. 209224, jan./jun. 2007.

GOODY, J. Literacy in traditional societies. Cambridge: CUP, 1968.

GUIMARÃES, A. M. de M. Letramento: muito além do jardim ou uma alfabetização sem limites ou datas marcadas. Calidoscópio, v. 4, n. 1, p. 60-65, jan./abr. 2006.

HEATH, S. B. What no bedtime story means: narrative skills at home and at school. Language in Society, v. 11, p. 49-76, 1982.

JAEGER, E. V. Letramento: perspectivas e implicações para a educação. Dialogia, v. 2, out. 2003, p. 33-40.

KLEIMAN, Â. B. Os significados do letramento: uma nova perspectiva sobre a prática social da escrita. Campinas, SP: Mercado de Letras, 1995.

. A construção de identidades em sala de aula: um enfoque interacional.

In: SIGNORINI, I. (Org.). Lingua(gem) e identidade: elementos para uma discussão no campo aplicado. Campinas, SP: Mercado das Letras, 2001. p. 267302.

. Professores e agentes de letramento: identidade e posicionamento social. Filologia e Linguistica Portuguesa, n. 8, p. 409-424, 2006.

. Letramento e suas implicações para o ensino de língua materna. Signo, Santa Cruz do Sul, v. 32, p. 1-25, dez. 2007.

MOITA LOPES, L. P. da. Discursos de identidade em sala de aula: a construção da diferença. In SIGNORINI, I. (Org.). Lingua(gem) e identidade: elementos para uma discussão no campo aplicado. Campinas, SP: Mercado das Letras, 2001. p. 303-330.

PELANDRÉ, N. L.; AGUIAR, P. A. de. Práticas de letramento na educação de jovens e adultos. Fórum Lingüístico, v.6, n.2, p. 55-65, jul-dez, 2009. 
PENNA, M. Relatos de migrantes: questionando as noções de perda de identidade e desenraizamento. In SIGNORINI, Inês (Org.). Lingua(gem) $e$ identidade: elementos para uma discussão no campo aplicado. Campinas, SP: Mercado das Letras, 2001. p. 89-112.

ORLANDI, E. Identidade lingüística escolar. In: SIGNORINI, I. (Org.). Lingua(gem) e identidade: elementos para uma discussão no campo aplicado. Campinas, SP: Mercado das Letras, 2001. p. 203-212.

PROCHNOW, D. de P. M.. As lições da Série Fontes no contexto da Reforma Orestes Guimarães em Santa Catarina. 2009. 148 f. Dissertação (Mestrado em Educação) Programa de Pós-Graduação em Educação. Universidade do Estado de Santa Catarina. Florianópolis, 2009.

SILVA, D. R. de S. Casa de barro: poesia para corações simples. São José, SC: Edição da autora, 2005. . Casa de pedras: poesia e prosa. São José, SC: Edição da autora, 2008.

SILVA, E. M. A influência do histórico de letramento dos sujeitos em suas práticas de leitura e escrita. Veredas FAVIP: Revista Eletrônica de Ciências, v. 2, n. 1 e 2, p. 51-59, jan.-dez. 2009.

SILVA, L. R. da; ARAÚJO, D. L. de. Correlação entre carta-protesto e histórico de letramento do candidato: uma análise de redações do vestibular. Linguagem em (Dis)curso, v. 10, n. 2, p. 315-338, maio/ago. 2010.

SOARES, M. Letramento: um tema em três gêneros. Belo Horizonte: Autêntica, 2009.

STREET, B. Literacy in theory and practice. Cambridge: CUP, 1984.

. What's 'new' in New Literacy Studies? Critical approaches to literacy in theory and practice. Current Issues in Comparative Education, v. 5, n. 2, p. 77-92, 12 May 2003. Disponível em:

< http://www.tc.columbia.edu/cice/Issues/05.02/52street.pdf > . Acesso em $11 / 3 / 2011$.

TFOUNI, L. V. Letramento e alfabetização. São Paulo: Cortez, 1995.

Recebido em: 24/10/11. Aprovado em: 21/08/12. 
Title: Literacy and construction of identity in senior age: a case study

Authors: Vidomar Silva Filho; Rosângela Hammes Rodrigues

Abstract: This article presents a case study of the literacy, in the realm of literature, of D., an elderly woman with four years of formal schooling. Based on the analysis of the literacy story of D., this study investigates the relationship between literacy and identity construction. In order to settle the theoretical bases of the study, a distinction is drawn between the autonomous and ideological models of literacy. The concepts of literacy practice, event, agent, and agency are presented. We also review the concept of identity. The case study presents the literacy story of D., examining the uses of reading and writing by D. and her family since D.'s childhood to the present day. We could observe a close relation between D. 's literacy in the realm of literature and the gradual construction of a writer identity, which allows her to express her being-in-world, to recover and rebuild her childhood memories and to access new social groups.

Keywords: Literacy. Literacy story. Literacy agent. Literacy agency. Identity construction.

Titulo: Alfabetismo y construcción de identidad en la terceira edad: un estudio de caso

Autores: Vidomar Silva Filho; Rosângela Hammes Rodrigues

Resumen: Este articulo presenta estudio de caso sobre el alfabetismo, en la esfera literaria, de D., una mujer anciana, con cuatro años de escolaridad formal. A partir del análisis del histórico de alfabetismo de $D$., se investiga la relación entre alfabetismo y construcción de identidad. Para fundamentar teóricamente el estudio, se establecen distinciones entre los modelos de alfabetismo autónomo e ideológico. Se presentan los conceptos de práctica, evento, agente y agencia de alfabetismo.También se revisa el concepto de identidad. En el estudio de caso, se presenta el histórico de alfabetismo de D., buscando rescatar los usos de la modalidad escrita por ella y su familia, desde la infância de D. hasta los días actuales. Se observa una estrecha relación entre el alfabetismo de D. en la esfera de la literatura y la constitución paulatina de una identidad de escritora, la cual le faculta expresar su estar-en el-mundo, recuperar y reconstruir sus memorias de infancia e inserirse en nuevos grupos sociales.

Palabras-clave: Alfabetismo. Histórico de alfabetismo. Agente de alfabetismo. Agencia de alfabetismo. Construcción de identidad. 